\title{
The Efficacy of Erbium, Chromium: Yttrium, Scandium, Gallium, Garnet laser in the removal of calcium hydroxide as intra canal medicament
}

\begin{abstract}
Ranu Hogir Sarhang ${ }^{(1)}$, Nawfal Abdulmelek Zakareya ${ }^{(2)}$
Background and objectives: Removal of calcium hydroxide from root canal system is difficult, and its residuals left on the dentin walls reduce the penetration of root canal sealers into dentinal tubules, resulting in a possible increase of apical leakage. This study evaluated the efficiency of two different techniques including Erbium, Chromium: Yttrium, Scandium, Gallium, Garnet (Er, Cr: YSGG) laser activated irrigation and conventional method on the removal of calcium hydroxide $\mathrm{Ca}(\mathrm{OH}) 2$.

Methods: Twenty extracted single-rooted teeth (upper second premolar, lower first and second premolars) with straight canals were prepared using ProTaper next rotary files up to size $x 5$. The root canals were filled with calcium hydroxide and putted inside the incubator for 1 week in 100\% humidity. The samples divided in to two groups in the first one conventional irrigation was used while in the second group ( $\mathrm{Er}, \mathrm{Cr}$ : YSGG) laser activation irrigation was used to remove $\mathrm{Ca}(\mathrm{OH}) 2$. After removel of calcium hydroxide the roots were split in to two halves and viewed under stereo microscope then surface area of remained $\mathrm{Ca}(\mathrm{OH}) 2$ was evaluated by Digimizer software. The data were analyzed statistically using one-way ANOVA, least significant differences (LSD) and post hoc test $95 \%$ confidence level $(P=0.05)$.

Results: The results of this study showed that the Er,Cr:YSGG laser activation irrigation was more powerful in the removal of $\mathrm{Ca}(\mathrm{OH}) 2$ in the apical and middle part of the root as compared to conventional irrigation $(P<0.001)$ but, in the coronal part of the root there was no significant difference between both groups.

Conclusion: $\mathrm{Er}, \mathrm{Cr}$ :YSGG laser activated irrigation is significantly better removal of $\mathrm{Ca}(\mathrm{OH}) 2$ in the apical and middle part of the root than conventional method, but did not provide complete removal of $\mathrm{Ca}(\mathrm{OH}) 2$.
\end{abstract}

Key Words: Calcium hydroxide, endodontics, laser activation, removal, conventional irrigation.

\footnotetext{
(1) Department of Conservative Dentistry, College of Dentistry, Tishk International University, Erbil, Iraq.

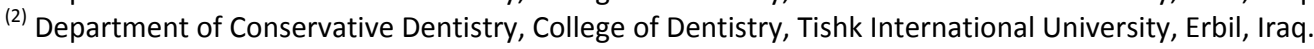
Correspondent Name: Ranu Hogir Sarhang

Email: ranuhogir@gmail.com
}

\section{Introduction}

A successful root canal treatment depends on the complete removal of bacteria, their byproducts and pulpal remnants from infected root canals and the complete sealing of the disinfected root canals because root canal system is a highly complex structure, in which there is difficulty for their cleaning and disinfection procedures as well as the removal of root canal dressing. A correct chemo-mechanical disinfection to eliminate the pulp tissue, the remains of dentin and microorganisms, thus eliminating the etiological factors that cause the endodontic infection. ${ }^{1}$ 
The main goal of intra-canal medication is to eliminate bacteria in the root canal, prevent bacterial proliferation between appointments, and act as a physicochemical barrier, preventing root canal reinfection and nutrient supply to the remaining bacteria. $^{2}$ It has been reported that calcium hydroxide pastes are difficult to remove from the root canal system, and its dressing residuals left on the dentin walls reduce the penetration of any root canal sealers into dentinal tubules, compromising the endodontic seal, resulting in a possible increase of apical leakage. ${ }^{3}$

Consequently, calcium hydroxide should be removed from the root canal walls before the root canal filling is placed in order to eliminate its unfavorable effects on bond strength, prior to root canal obturation, by removing the calcium hydroxide completely from root canal system will minimize a negative influence of calcium hydroxide dressing on root filling materials. ${ }^{4}$

Residual $\mathrm{Ca}(\mathrm{OH}) 2$ on canal walls not only interact with some sealers changing its physical properties, reducing the flow and setting time but also prevents the penetration of sealer into the dentinal tubules and might increase apical leakage of gutta-percha root fillings especially with zinc oxide-eugenol sealer. ${ }^{5}$

Thus, different methods have been introduced over the years to improve removal of calcium hydroxide intracanal dressing which includes use of patency files, rotary instruments, and different sonic and ultrasonic devices for activation of an intracanal irrigants to improve the flushing action of the solution. ${ }^{5}$ The most frequently used method is Mechanical instrumentation with hand $\mathrm{K}$ file (master apical file) with copious irrigation with sodium hypochlorite $(\mathrm{NaOCl})$ and EDTA. ${ }^{7}$ Though sonic and ultrasonic devices are requested to be more effective however, till now there is no general consensus regarding the best method for the removal of intracanal $\mathrm{Ca}$ (OH)2. ${ }^{4,5}$
Laser activated irrigation has been proposed to remove debris, smear layer, triple antibiotic paste and intra-canal medicament from the root canal. The most common lasers that have been investigated and have shown favorable results are Erbium: Yttrium, Aluminum, Garnet (Er:YAG) and Erbium, Chromium: Yttrium, Scandium, Gallium, Garnet (Er,Cr:YSGG) laser. It has been shown that the laser-activated irrigation enhancing fluid exchange and assisting in removal of debris by creating explosive vapor bubbles inside the root canal with secondary cavitation effects. Similarly, Er,Cr:YSGG laser driven irrigation improves the removal of smear layer in the root canal. ${ }^{7}$ The aim of this study was to evaluate the efficacy of Er,Cr:YSGG laser on the removal of calcium hydroxide as intra-canal medicament.

\section{Materials and methods}

Twenty single-canal human extracted teeth (upper second premolar, lower first and second premolars) were used in this study, age of the patient between 25-35 years were selected. The external root surfaces were scaled with ultrasonic scaler to remove any soft tissue or calculus from the root surface. Subsequently, the teeth were store in saline solution until they will be used. the criteria for tooth selection was include one single root canal; no fractures, or cracks; and a completely formed apex on visual examination.

The working length was determined $1 \mathrm{~mm}$ short of the length at which a $\# 10 \mathrm{~K}$ file extruded apically using stereo microscope the working length was standardized for all the specimens to $11 \mathrm{~mm}$ then the specimens de-coroneted to that working length using a diamond disc then the apex of all samples was sealed with sticky wax to simulate the closed environment of a clinical situation and immerse into a polyethylene ring full of impression material rubber base (alphasil ${ }^{\circledR}$ PERFECT - Standard C-silicone). The patency of the canals was verified by passing a file size \#K-10 through the apical 
foramina by checking it under stereo microscope if the file does not appear at the end of apical foramina and fail to check the patency we excluded it. The root canals were instrumented by using NSK Endo-mate DT Endomotor rotary according to the manufacturer instruction (speed 300 RPM, torque $2.4 \mathrm{Ncm}$ ) and ProTaper Next (Dentsply Maillefer) files the instrumentation sequence was as follows: $\mathrm{x} 1, \mathrm{x} 2, \mathrm{x} 3$, $\mathrm{x} 4 \times 5$.

Between each instrument, the canals were conventionally irrigated with $5 \mathrm{ml}$ of $5.25 \%$ sodium hypochlorite $(\mathrm{NaOCl})$ (Tehno Dent Co., Belgorod Russia) and rinsed with $5 \mathrm{ml}$ $17 \%$ EDTA (Prevest DenPro Jammu India) for 30 seconds, followed by a final rinse of $5 \mathrm{ml}$ distilled water with the 27-gauge end-closed double side vent needle. During the irrigation, the needle was used in an up-down motion within the apical third ( $2 \mathrm{~mm}$ short of WL) for 30 seconds, the needle depth was standardized for each canal by placing the rubber stopper $2 \mathrm{~mm}$ short of the working length. ${ }^{8}$

After drying the canals with paper points (Dentsply Maillefer), all the de-coronate root samples were received a paste of Metapex (Meta Biomed Co., Cheongju, Korea) with iodoform was injected into each canal with the help of a Lentulo spiral size \#40 used in a clockwise rotation with a low speed hand piece $5000 \mathrm{rpm}$ ( $2 \mathrm{~mm}$ short of WL) for 30 seconds, to be assure that the paste is well distributed and attached to the canal walls. ${ }^{9}$

The access cavities were temporarily sealed with injectable glass ionomer cement capsule and gun (Ionoglas Fill Extra Harverd OptiCaps Germany) as temporary filling material by using a round diamond bure without water to remove $1 \mathrm{~mm}$ of the calcium hydroxide from the coronal part, one capsule of Glass Ionomer cement was used for one sample. The samples were then placed in a gauze saturated with distilled water and incubated in $100 \%$ relative humidity at $37{ }^{\circ} \mathrm{C}$ for 7 days. to provide standardization, all procedures was carried out by the same operator.

Control group, conventional irrigation. the temporary restoration was removed then in this group $(n=10)$ using $5.25 \%$ $\mathrm{NaOCl}$ and $17 \%$ EDTA, the removal of $\mathrm{Ca}$ $(\mathrm{OH})_{2}$ was performed by using a conventional irrigation needle with $5 \mathrm{ml}$ of $5.25 \% \mathrm{NaOCl}$ followed by $5 \mathrm{ml}$ of $17 \%$ EDTA total irrigation for 60 seconds and then rinse it with $5 \mathrm{ml}$ of distal water for 30 seconds. The needle was used in an up -down motion within the apical third. The needle depth was standardized for each canal by placing the rubber stopper $2 \mathrm{~mm}$ short of the working length. ${ }^{10}$

Experimental group, Er, Cr: YSGG laser activated irrigation. The temporary restoration was removed then in this group $(\mathrm{n}=10)$ The Waterlase MD dental laser (Biolase, CA, USA) was used at panel settings according to manual guideline of 0.75-watt average power and 20 hertz, air and water were switched off at focused through an endodontic RFT2 tip-25 of 275 $\mu \mathrm{m}$ diameter. $5.25 \% \mathrm{NaOCl}$ was deposited the canal and activated by a $2780 \mathrm{~nm}$ wavelength Erbium chromium: YttriumScandium-Gallium-Garnet (Er,Cr:YSGG) a total activation was 60 seconds . Followed by irrigation with $17 \%$ EDTA solution a total irrigation was 60 seconds then rinsed with $5 \mathrm{ml}$ of distal water for 30 seconds. The tip of the optic fiber (RFT2) was placed $3 \mathrm{~mm}$ from the WL and it was withdrawing gently from the apical to the coronal region with helical movement and reintroduced to the apex. ${ }^{7}$

Longitudinal grooves had been created on the cementum of both side buccal and lingual root surfaces without damaging the inner layer of dentine around the canal by increasing the depth step by step deep in to the dentine for $1 \mathrm{~mm}$ cervically then decreasing the depth apically in each step we check it under stereo microscope for confirmation if the inner layer of dentine damaged the sample was excluded, then the roots were split longitudinally by using a chisel. the specimens were allocated in to 


\section{Result}

The results of two groups (Er, Cr: YSGG laser and control) showed that the $\mathrm{Er}, \mathrm{Cr}$ : YSGG laser activated irrigation is more powerful than conventional technique in the removal of calcium hydroxide. (Figure 1) shows that the mean surface area of the conventional technique was $19.12 \mathrm{~mm}$ which was significantly higher than the mean $(2.87 \mathrm{~mm})$ of the Er, Cr: YSGG Laser $(\mathrm{p}<0.001)$.

It is evident in (Table 1) that no remaining calcium hydroxide was detected in the coronal part of the root for both groups (Figure 2. A and B), while in the middle part, the mean remaining area using the conventional technique was $18.61 \mathrm{~mm}$ which was significantly $(\mathrm{p}=0.007)$ higher than the mean of remaining area when the Er, Cr: YSGG LASER was used $(4.23 \mathrm{~mm})$. The same pattern was observed in the apical part of the root where the mentioned area was $52.93 \mathrm{~mm}$ using the conventional method compared with 12.68 using the Er, Cr: YSGG LASER method $(\mathrm{p}<0.001)$.

It is evident in (Figure 2) That the remaining calcium hydroxide was calculated as a mean surface area by a Digimizer software and the remnant of calcium hydroxide was greatly more in apical and middle part of conventional method than in apical and middle part of the Er, Cr: YSGG laser

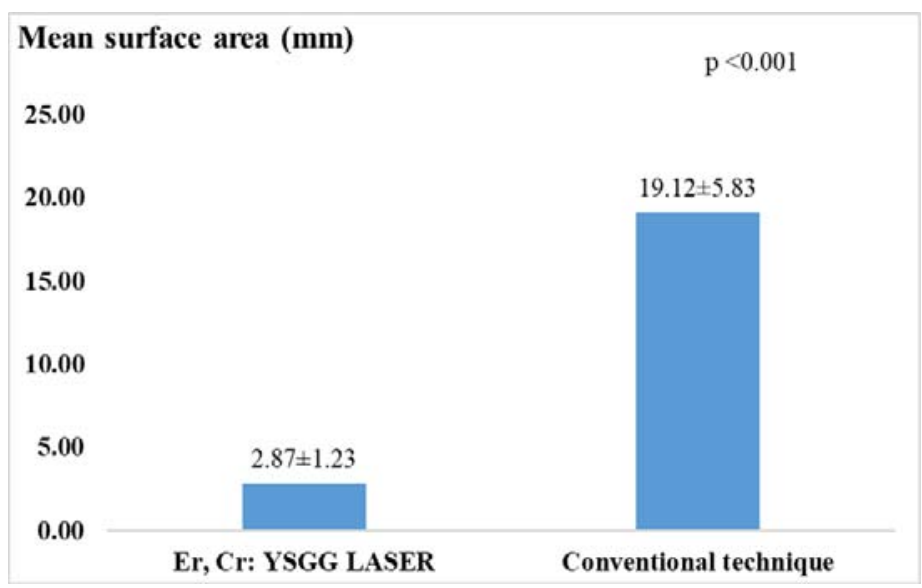

Figure 1. Mean surface area of remaining calcium hydroxide inside the root canals by the Er, Cr: YSGG LASER and the conventional technique showing great difference than conventional technique.
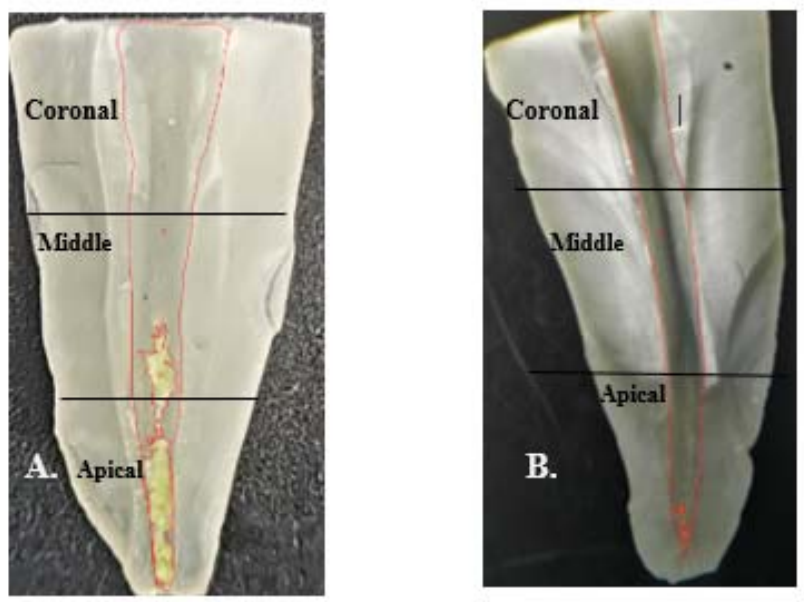

Figure 2. calculation of the surface area of the remaining calcium hydroxide in over all the canal by Digimizer software. A) conventional methode. B) Er, Cr: YSGG laser activated irrigation showing maximum removal of calcium hydroxide 
Table 1. Mean surface area of the remaining calcium hydroxide in the middle, apical, and coronal part of the root by Er, Cr: YSGG LASER and the conventional technique.

\begin{tabular}{|c|c|c|c|c|c|}
\hline $\begin{array}{c}\text { Part of } \\
\text { root }\end{array}$ & Method & $\mathbf{N}$ & $\begin{array}{c}\text { Mean surface area of remaining cal- } \\
\text { cium hydroxide }(\mathbf{m m})\end{array}$ & $( \pm S D)$ & $\mathbf{p}$ \\
\hline \multirow{2}{*}{ Coronal } & Er, Cr: YSGG LASER & 10 & 0.00 & $( \pm 0.00)$ & NA* $^{*}$ \\
\cline { 2 - 7 } & Conventional technique & 10 & 0.00 & $( \pm 0.00)$ & \\
\hline \multirow{2}{*}{ Middle } & Er, Cr: YSGG LASER & 10 & 4.23 & $( \pm 8.64)$ & 0.007 \\
\cline { 2 - 7 } & Conventional technique & 10 & 18.61 & $( \pm 10.29)$ & 0.001 \\
\hline \multirow{2}{*}{ Apical } & Er, Cr: YSGG LASER & 10 & 12.68 & $( \pm 14.50)$ & \\
\cline { 2 - 7 } & Conventional technique & 10 & 52.93 & & \\
\hline
\end{tabular}

*t cannot be computed because the standard deviations of both groups are 0 .

\section{Discussion}

This study was designed to evaluate the effectiveness of Er,Cr:YSGG laser activation of irrigation in comparison to conventional irrigation technique in removing $\mathrm{Ca}(\mathrm{OH}) 2$ from root canals. The results of this study showed that the Er, Cr: YSGG laser activated irrigation was more effective in the removal of the medication than needel irrigation. The mean surface area of the Er, Cr: YSGG was $2.87 \pm 1.23$ $\mathrm{mm}$ and it was statistically superior to the mean surface area of conventional technique which it was $19.12 \pm 5.83 \mathrm{~mm}$ (Figure 1) in removing of $\mathrm{Ca}(\mathrm{OH}) 2$ This could be attributed to the capability of laser -driven irrigation to generate cavitation and a turbulent flow to create a gaseous bubble at the laser tip as the irrigant is vaporized, resulting in expansion of a bubble as the laser continues to emit energy and evaporates the irrigant at the leading edge. ${ }^{11}$ At the end of the cycle, the vapor cools, causing the bubble to collapse and separate from the firing tip. The alternating bubble expansion and implosion create a shear stress along the canal wall, facilitating the detachment of $\mathrm{Ca}(\mathrm{OH}) 2$ remnants and their subsequent removal by the irrigation procedure. $^{11}$
The result of our study agree with the study of Kustarc1 et al., they used Er,Cr:YSGG laser activation with different irrigating solutions $(\mathrm{NaOCl}$, EDTA, QMix 2in1, and peracetic acid ) to remove $\mathrm{Ca}(\mathrm{OH}) 2$ from an artificial groove created in straight root canals, and they compared it to needle irrigation with the same irrigating solutions. They found that the complete removal of $\mathrm{Ca}(\mathrm{OH}) 2$ from the grooves was not obtained. However, activation of the irrigant with the laser was shown to be more effective than needle irrigation in removing $\mathrm{Ca}(\mathrm{OH}) 2$ from the root canal walls. $^{12}$

Needle irrigation is the standard procedure for root canal irrigation, but unfortunately, this technique is not efficient in the apical part of the root canal. ${ }^{13}$ It is particularly difficult to completely remove the residual smear layer, debris, or calcium hydroxide in that part because the apical part's dimension and complex anatomy do not allow the circulation and action of the irrigating solutions. ${ }^{14}$ For this reason, the use of laser agitation with different wavelengths, has been proposed as an adjunct to conventional endodontic cleaning procedures. ${ }^{13,15-18}$

In the present study, samples with both 
Er,Cr:YSGG activation irrigation and conventional technique showed $100 \%$ removal of $\mathrm{Ca}(\mathrm{OH}) 2$ in the coronal part of the root (Figure 2. A and B) and that because of the wideness of that part that easily allow the circulation and action of irrigants, ${ }^{14}$ but in the middle and apical third of the root the Er,Cr:YSGG laser was much more effective than conventional irrigation group. (Table 1) because mechanism for the laser activation of irrigating solutions originates from the absorption of laser energy, the formation of vapor bubbles, the collapse of the bubbles, acoustic streaming, and, finally, cavitation and lead to detachment of calcium hydroxide ${ }^{17}$ while in conventional method is depend only on mechanical movement of fluids.

Er,Cr:YSGG laser has been shown to effectively remove debris and smear layer from the apical region of a root canal, ${ }^{18}$ other studies have shown disagreement with our result and that's due to they used different methods to remove calcium hydroxide. ${ }^{8,17}$ The results of this investigation were in agreement with the study of Dua, he concluded that none of the irrigation methods (5\% NaOCl and \%17 EDTA) could completely remove $\mathrm{Ca}(\mathrm{OH}) 2$ from the apical third of the root canal, Er,Cr:YSGG laser assisted irrigation could significantly remove higher volume of $\mathrm{Ca}(\mathrm{OH}) 2$ from the coronal, middle and apical thirds of the root canal in comparison to conventional needle irrigation. ${ }^{7}$

\section{Conclusion}

Within the limitation of this study we concluded that Er,Cr:YSGG laser assisted irrigation is significantly more powerful than conventional technique, but did not provide complete removal of calcium hydroxide. While in the coronal part there is no significant difference between both groups but, in the middle and apical part there is significant difference between both groups.

\section{Conflicts of interest}

The authors reported no conflict of interest.

\section{References}

1. Prada I, Micó-Muñoz P, Giner-Lluesma T, MicóMartínez $\mathrm{P}$, Muwaquet-Rodríguez $\mathrm{S}$, AlberoMonteagudo A. Update of the therapeutic planning of irrigation and intracanal medication in root canal treatment. A literature review. J Clin Exp Dent. 2019;11(2): e185193.

2. Ingle JI, Bakland LK, Baumgartner JC. Ingle"s Endodontics 6th ed. BC Deckerlnc; Hamilton; 2008; p.999, 1009-11.

3. Nandini S, Velmurugan N, Kandaswamy D. Removal efficiency of calcium hydroxide intracanal medicament with two calcium chelators: volumetric analysis using spiral CT, an in vitro study. J Endod. 2006; 32(11): 1097-101.

4. Salgado RJ, Moura-Netto C, Yamazaki AK, Cardoso LN, de Moura AA, Prokopowitsch I. Comparison of different irrigants on calcium hydroxide medication removal: microscopic cleanliness evaluation. Oral Surgery, Oral Medicine, Oral Pathology, Oral Radiology, and Endodontology. 2009; 107(4):580-84. .

5. Athanassiadis B, Abbott PV, Walsh L. The use of calcium hydroxide, antibiotics and biocides as antimicrobial medicaments in endodontics. Aust Dent J. 2007; 52:64-82.

6. Tamil S, Andamuthu S, Vaiyapuri R, Prasad A. S. , Jambai S, and Chittrarasu M. A Comparative Evaluation of Intracanal Calcium Hydroxide Removal with Hand File, Rotary File, and Passive Ultrasonic Irrigation: An In Vitro Study. J Pharm Bioallied Sci. 2019; 11: S442-S445. Dua, D.A. Eeficacy of Laser on calcium hydroxide removal from root canals; 2017.

7. Laky $M$, Volmer $M$, Arslan $M$, Agis $H$, Moritz A, and Cvikl B. Efficacy and Safety of Photon Induced Photoacoustic Streaming for Removal of Calcium Hydroxide in Endodontic Treatment. BioMed Research International 2018; 1-6.

8. ASLAN T, DÜZGÜN S, ÜSTÜN Y. Effect of lentulo spiral usage at deferent speeds on apical extrusion of calcium hydroxide. 2018; 28(2):133-37

9. Chawla A, Kumar V. Evaluating the efficacy of different techniques and irrigation solutions for removal of calcium hydroxide from the root canal system: A scanning electron microscope study. J Conserv Dent. 2018; 21(4): 394-400.

10. Blanken JW, Verdaasdonk RM. Cavitation as a working mechanism of the Er,Cr:YSGG laser in endodontics: a visualization study. The Journal of Oral Laser Applications.2007; 7, 97-106.

11. Kuştarcı, A., Er, K., Siso, S. H., Aydın, H., Harorlı, H., Arslan, D., et al. Efficacy of Laser-Activated Irrigants in Calcium Hydroxide Removal from the Artificial Grooves in Root Canals: AnEx VivoStudy. Photomedicine and Laser Surgery. 2016; 34 
(5), 205-210.

12. Capar I, Ozcan E, Arslan H, Ertas H, Aydinbelge H. Effect of different final irrigation methods on the removal of calcium hydroxide from an artificial standardized groove in the apical third of root canals. J Endod. 2014; 40:451-54.

13. Arslan H, Ayrancı LB, Karatas E, Topc, uog lu HS, Yavuz MS, Kesim B. Effect of agitation of EDTA with 808nanometer diode laser on removal of smear layer. J Endod. 2013; 39(12):1589-92. Bodrumlu E, Avsar A, Hazar Bodrumlu E, Cicek E. The effects of calcium hydroxide removal methods on bond strength of Epiphany SE with two irrigation protocols. Acta Odontol Scand 2013; 71:989-93.

14. Arslan H, Gok T, Saygili G, Altintop H, Akcay M, Capar ID. Evaluation of effectiveness of various irrigating solutions on removal of calcium hydroxide mixed with $2 \%$ chlorhexidine gel and detection of orange-brown precipitate after removal. J Endod 2014 a; 40(11):1820-1823.
15. Arslan H, Akcay M, Capar ID, Saygili G, Gok T, Ertas H. An in vitro comparison of irrigation using photon-initiated photoacoustic streaming, ultrasonic, sonic and needle techniques in removing calcium hydroxide. Int Endod J 2014 b; 48(3):246-51.

16. Peeters HH, Suardita K. Efficacy of smear layer removal at the root tip by using ethylenediaminetetraacetic acid and erbium,chromium:yttrium, scandium, gallium garnet laser. J Endod 2011; 37(11):1585-89. 